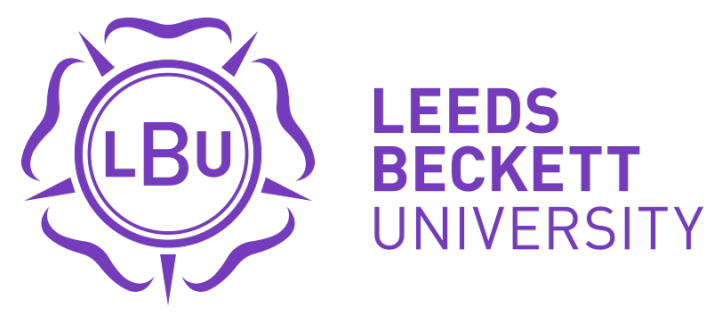

Citation:

Tierney, GJ and Kuo, C and Wu, L and Weaving, D and Camarillo, D (2020) Analysis of head acceleration events in collegiate-level American football: A combination of qualitative video analysis and in-vivo head kinematic measurement. Journal of Biomechanics, 110. ISSN 0021-9290 DOI: https://doi.org/10.1016/j.jbiomech.2020.109969

Link to Leeds Beckett Repository record:

https://eprints.leedsbeckett.ac.uk/id/eprint/7020/

Document Version:

Article (Accepted Version)

Creative Commons: Attribution-Noncommercial-No Derivative Works 4.0

The aim of the Leeds Beckett Repository is to provide open access to our research, as required by funder policies and permitted by publishers and copyright law.

The Leeds Beckett repository holds a wide range of publications, each of which has been checked for copyright and the relevant embargo period has been applied by the Research Services team.

We operate on a standard take-down policy. If you are the author or publisher of an output and you would like it removed from the repository, please contact us and we will investigate on a case-by-case basis.

Each thesis in the repository has been cleared where necessary by the author for third party copyright. If you would like a thesis to be removed from the repository or believe there is an issue with copyright, please contact us on openaccess@leedsbeckett.ac.uk and we will investigate on a case-by-case basis. 


\title{
Analysis of head acceleration events in collegiate-level American football: A combination of qualitative video analysis and in-vivo head kinematic measurement
}

\author{
Gregory J. Tierney ${ }^{[1]}$
}

Calvin Kuo ${ }^{[2]}$

Lyndia Wu ${ }^{[3]}$

Dan Weaving ${ }^{[4]}$

David Camarillo ${ }^{[5]}$

${ }^{[1]}$ School of Biomedical Sciences, University of Leeds, UK

${ }^{[2]}$ School of Kinesiology, University of British Columbia, Canada

${ }^{[3]}$ Department of Mechanical Engineering, University of British Columbia, Canada

${ }^{[4]}$ Carnegie Applied Rugby Research Centre, Leeds Beckett University, UK

${ }^{[5]}$ Department of Bioengineering, Stanford University, USA

Word Count: 2790

Abstract Word Count: 246

Key Words: Concussion; Biomechanics; Instrumented Mouthguards; Video Analysis

Number of Figure: 3

Number of Tables: 2

Corresponding Author:

Dr Gregory J. Tierney

4.02 Miall Building

School of Biomedical Sciences

University of Leeds

Leeds, UK,

LS2 9NL

Tel +44 (0)1133435084

Email g.tierney@leeds.ac.uk 


\title{
Analysis of head acceleration events in collegiate-level American football: A combination of qualitative video analysis and in-vivo head kinematic measurement
}

\begin{abstract}
The contact nature of American football has made head acceleration exposure a concern. We aimed to quantify the head kinematics associated with direct helmet contact and inertial head loading events in collegiate-level American football. A cohort of collegiate-level players were equipped with instrumented mouthguards synchronised with time-stamped multiple camera-view video footage of matches and practice. Video-verified contact events were identified as direct helmet contact or inertial head loading events and categorised as blocking, blocked, tackling, tackled or ground contact. Linear mixed-effects models were utilised to compare peak head kinematics between contact event categories. The timestamp-based cross-verification of the video analysis and instrumented mouthguard approach resulted in 200 and 328 direct helmet contact and inertial head loading cases, respectively. Median linear acceleration, angular acceleration and angular velocity for inertial head loading cases was greater than direct helmet contact events by $8 \%(\mathrm{p}=0.007), 55 \%(\mathrm{p}<0.001)$ and $4 \%(\mathrm{p}=0.007)$, respectively. Median head kinematics for all contact event categories appeared similar with no pairwise comparison resulting in statistical significance $(p>0.05)$. The study highlights the potential of combining qualitative video analysis with in-vivo head kinematics measurements. The findings suggest that a number of direct helmet contact events sustained in American football are of lower magnitude to what is sustained during regular play (i.e. from inertial head loading). Additionally, the findings illustrate the importance of including all contact events, including direct helmet contact and inertial head loading cases, when assessing head acceleration exposure and player load during a season of American football.
\end{abstract}




\section{Introduction}

American football is a dynamic and high-impact collision sport. Contact events are usually initiated through blocking and tackling (Lessley et al., 2018). The physical and high-impact nature of American football and similar contact sports has made concussion a concern (Lessley et al., 2018). The concussion incidence in the NFL was recently estimated to be greater than 0.6 concussions per game (Nathanson et al., 2016). Concussion prevention has become a priority in American football due to the growing concern surrounding its medium and long-term consequences. A growing evidence base suggests that after a concussion, athletes have a higher risk of sustaining another concussion and musculoskeletal injuries (Cross et al., 2016, Abrahams et al., 2014). A growing body of literature also suggests a potential long-term relationship between repeated concussion injuries and chronic traumatic encephalopathy and its associated neurological conditions (Stern et al., 2011).

Furthermore, there is a concept that repeatedly engaging in sub-concussive impacts can have an adverse effect on brain health (Stern et al., 2011, Baugh et al., 2012). Sub-concussion has previously been defined by head motions "that do not result in symptoms typically used to define concussion such as loss of consciousness, amnesia, confusion and headache" (Merchant-Borna et al., 2016). This definition presents some challenges as a lower threshold for sub-concussive impacts has not been established. However, for practical purposes, impacts that result in less than $10 \mathrm{~g}$ head acceleration have generally not been considered (Beckwith et al., 2013). Head impacts under 10g have been reported for activities such as walking, jumping, running, and sitting, and thus are considered non-impact events (Ng et al., 2006). Although the long-term effects are not yet fully understood, it is postulated that repeatedly engaging in sub-concussive impacts may influence long term neurodegeneration (Baugh et al., 2012, Stern et al., 2011). However, more longitudinal research studies are needed as large gaps remain in our understanding of the relationships between playing contact sports and long-term brain health in retired athletes (Cunningham et al., 2018). Concussion prevention strategies by college football governing bodies have focused on limiting athlete head impact frequency and severity during practices. For example, the Ivy League and Pac-12 conferences have placed restrictions on the amount of contact permitted in practice for American football (Baugh and Kroshus, 2016). In 2017, the NCAA eliminated 
two-a-day practices during the preseason for all Division I Football Bowl Subdivision programs (Stemper et al., 2019). However, a recent study found this intervention to have an unintended consequence with teams showing an increase in head impact exposure during the preseason (Stemper et al., 2019). It was indicated that this was mainly due to increased contact intensity over the same number of practice sessions (Stemper et al., 2019). One study recently found that reducing player contact speed and improving contact technique were effective methods for reducing head impact exposure in youth American football (Kelley et al., 2018).

Measurement of head kinematics during sports collisions is essential for understanding the severity and mechanism of concussion injuries (Wu et al., 2016b). In American football, most studies have used helmet-based sensor approaches (Brolinson et al., 2006, Duma et al., 2005, Rowson et al., 2012). More recently in American football, studies have used mouthguard-based sensor approaches. However the studies have tended to focus on quantifying the false-positive rates of the sensors (Kuo et al., 2018, Bartsch et al., 2019) or do not involve video review (Kawata et al., 2017). A plethora of biomechanical research has linked head kinematics of a single impact event to concussion and other brain injuries (Pellman et al., 2003, Viano et al., 2007). However, it has also been argued that the number and magnitude of sub-concussive hits and the time between hits should all be considered (Merchant-Borna et al., 2016, Stemper et al., 2018). Recent studies illustrated that increased levels of repetitive head acceleration exposure in contact sports may be a second biomechanical mechanism for concussion (Stemper et al., 2018, Talavage et al., 2014). Therefore, more frequent or severe head accelerations may reduce an athlete's tolerance for injury, making them increasingly susceptible to concussion from lower magnitude head impacts (Stemper et al., 2018). This clearly illustrates the importance of monitoring head kinematics in practices and matches. Additionally, we need to know more about the head kinematics experienced during inertial head loading cases (i.e. head accelerations from forces transmitted through the neck) and specific contact events (e.g. tackling and blocking) in order to guide strategies to reduce the head acceleration exposure environment in American football (Tierney et al., 2018b, Tierney and Simms, 2017). 
In this study, we equipped players from a NCAA Division I American football team with instrumented mouthguards to measure head kinematics during regular season matches and practice (Kuo et al., 2018). Separately and independently, qualitative video analysis of each match and practice was conducted to categorise the contact events for each player equipped with an instrumented mouthguard. The combined approach enabled a qualitative assessment of video-verified head acceleration events in order to identify a difference in head kinematics between different contact events.

\section{Methods}

This study utilised the dataset from Kuo et al. (2018) by analysing video footage of contact events involving players equipped with instrumented mouthguards during the Stanford University American football 2015 fall season. A total of seven players were recruited through the Stanford Internal Review Board (IRB \#34943) representing mainly offensive playing positions for a number of matches and practices, see Table 1. The mouthguards were custom-fit using upper dentition impressions moulds. The mouthguards were instrumented with accelerometers and gyroscopes to record 3D-head kinematics on the field. The tri-axial linear accelerometer (H3LIS331) and tri-axial gyroscope (ITG3701A) were both sampling at $1000 \mathrm{~Hz}$. Wu et al. (2016a) found that for helmeted impacts, $1000 \mathrm{~Hz}$ sample rate with $500 \mathrm{~Hz}$ bandwidth on the accelerometer can achieve less than $10 \%$ attenuation in the peak. The mouthguards utilized in this study were previously validated in both cadaveric and anthropomorphic dummy testing in impact conditions typical of American football and with an American football helmet (Kuo et al., 2016). The mouthguard is thought to be an ideal form factor for measuring head impact kinematics as it couples directly to the upper dentition, which itself is attached to the skull via stiff ligaments. These mouthguards were shown to measure linear acceleration and angular velocity within $10 \%$ of reference measurements at the head center of gravity (COG). Angular acceleration measurements typically underestimated reference measurements by up to $20 \%$, likely due to bandwidth limitations of the angular rate gyroscope (Wu et al., 2016a). While mandible interactions might affect the accuracy of the mouthguard, previous validation suggests that mandible interactions produce high frequency signals in the $80-100 \mathrm{~Hz}$ range, and thus we removed impacts with peak content in this frequency range as likely having measurement artefacts from the mandible (Kuo et al., 2016). 
The mouthguard recorded linear and angular kinematic time histories over 100ms around a typical 10g head COG linear acceleration magnitude threshold (10ms pre-impact, 90ms post-impact). Linear accelerations were transformed back to the head COG using rigid body dynamics assumptions (Kuo et al., 2018). Impacts collected on the instrumented mouthguards were time stamped with 1 second resolution enabling synchronisation with the video footage. For this study, a head acceleration event was defined as any impact that exceeded the head COG 10g linear acceleration magnitude threshold, and thus included direct helmet contact cases and inertial head loading cases.

\section{Insert Table 1 near here}

A two stage multiple-camera view video analysis approach was undertaken for all contact events. All cameras recorded at 30 frames-per-second and a resolution of 1080p. For the first round of video analysis, trained raters were tasked with tracking one player in each video and labelling their activity as

either Direct Helmet Contact, Inertial Head Loading, No Contact, Obstructed View, Idle, and Not in Video. Kuo et al. (2018) found that the trained raters correctly classified an average of $88 \%$ of the direct helmet contact events as part of a reliability analysis. Each contact event was categorised based on the player activity i.e. blocking, blocked, tackling, tackled and ground contact, see Figure 1 (Lessley et al., 2018). The timestamp from each video-based contact event was cross-referenced with the instrumented mouthguard reading. No diagnosed concussions were sustained by the cohort when taking part in this study.

All statistical analyses were conducted in R Studio. Our dependent variables included peak linear acceleration, peak angular acceleration and peak angular velocity, treated as continuous variables. Independent variables included the contact event categories of blocked, blocking, ground, tackled, tackling which were treated as categorical variables. The data were visually inspected for normality using histograms and Q-Q plots. The data did not always follow an approximated normal distribution and were consequently expressed as the median and quartile range (lower [25\%] to upper [75\%] quartiles). As a result, to reduce the error from non-uniform data, all dependent variables were logtransformed prior to analysis. 
Our design located units of analysis (e.g. linear and angular head accelerations) nested in clusters of units (i.e. different players and matches/training). We therefore adopted linear mixed-effects models (via lme4 package) to compare peak linear accelerations, peak angular accelerations and peak angular velocities between the contact event categories (Model 1) and between body and helmet contacts (Model 2). For model 1, player and match/training identification numbers were included as random intercepts to account for the between-player and between-match variability in the dependent variables. Contact event category was entered as a separate categorical fixed effect to compare differences between the contact events for the dependent variables. For model 2, player and match/training identification, and tackle category were included as random intercepts with body and helmet contacts included as a categorical fixed effect to compare differences between the two contact types for each of the dependent variables. Effect size differences (95\% confidence intervals) were estimated for each of the comparisons from the ratio of the observed mean difference to the pooled standard deviation (random effects and the residual error). These were qualitatively interpreted as trivial $(<0.2)$, small $(0.2$ to $<0.60)$, moderate $(0.60$ to $<1.20)$, large $272(1.20$ to $<2.00)$ and very large $(\geq 2.0)$. For all comparisons, $\mathrm{p}$ values were used to determine significance, with an alpha level set at $\mathrm{p}<0.05$.

\section{Insert Figure 1 near here}

\section{Results}

The timestamp-based cross-verification of the video analysis and instrumented mouthguard approach resulted in 528 contact events (200 and 328 direct helmet contact and inertial head loading cases, respectively) being labelled with the majority occurring in the blocking phase of play. Inertial head loading cases resulted in higher head kinematics than direct helmet contact events, with (Figure 2). Median linear acceleration, angular acceleration and angular velocity for inertial head loading cases was greater than direct helmet contact events by $8 \%(\mathrm{p}=0.007 ; \mathrm{ES}=0.229$; Interpretation=Small), $55 \%$ $(\mathrm{p}<0.001 \mathrm{ES}=0.366 ;$ Interpretation=Small $)$ and $4 \%(\mathrm{p}=0.007 ; \mathrm{ES}=0.232 ;$ Interpretation=Small $)$ respectively.

\section{Insert Figure 2 near here}


Median head kinematics for all contact event categories appear similar (Figure 3). A maximum percentage difference was identified between Tackling and Tackled for peak linear acceleration, with tackling resulting in $47 \%$ higher median linear acceleration than being tackled. In contrast, a maximum percentage difference was identified between Tackling and Tackled for peak angular acceleration, with being tackled resulting in 56\% higher median angular acceleration than tackling. Ground contacts resulted in the highest median peak head angular velocity values. No contact event pairwise comparison for the peak head kinematics resulted in statistical significance ( $p>0.05)$ with all effect sizes interpreted at trivial or small (Table 2).

\section{Insert Figure 3 near here}

\section{Insert Table 2 near here}

\section{Discussion}

This study utilised an instrumented mouthguard and independent video analysis protocol to assess differences between head kinematics from various contact events from a cohort of collegiate level American football players throughout fall season. The study quantified the median head kinematics for blocking, blocked, tackling, tackled and ground contact events in American football, the magnitudes of which appear similar. The findings illustrate that it is important to include all contact events, including direct helmet contact and inertial head loading cases, when assessing head acceleration exposure and player load during a season of American football. For a given impact condition, it is expected that direct helmet contact would result in higher head kinematics than inertial head loading from an impact to the body. This explains why the majority of concussions in American football are from direct helmet contact(Lessley et al., 2018), and thus biomechanical research has focused on direct helmet contact events (Pellman et al., 2003, Viano et al., 2007, Kuo et al., 2018). However, the incidence of direct helmet contacts events that result in head kinematics similar to reported values concussive injuries did not occur in this study. Instead, head kinematics from inertial head loading events were of higher magnitude than direct helmet contacts events and occurred more frequently. This suggests that a number of direct helmet contact events sustained in American football are not of the magnitude that would result 
in a concussion injury. Instead they are of similar magnitude to what is sustained during regular play (i.e. from inertial head loading).

The methodology utilised in this study highlights the importance of a combined biomechanical (instrumented mouthguard) and qualitative (video analysis) approach for further understanding phase of play-specific head kinematics in contact sports. Qualitative video analysis approaches alone generally focus on direct-head/helmet contact events, and thus miss vital information from inertial head loading events (Tierney et al., 2016b). Biomechanical instrumented mouthguard approaches alone without video verification may be prone to false-positive readings (Kuo et al., 2018). Furthermore, it provides little information on the causes of impacts that trigger the mouthguard which is essential for guiding head acceleration exposure and concussion prevention strategies. Clearly examining and monitoring the extent to which practices can be modified to reduce contact is an important step (Baugh and Kroshus, 2016, Stemper et al., 2019). Reducing the intensity of contact practices could be an effective method in reducing head impact exposure and severity, particularly for players that have been exposed to a high number of measured head accelerations in recent matches or practices.

Video analysis is a time consuming process, and thus has limited feasibility for everyday use. However, biomechanical and automation techniques are evolving (Xing et al., 2010, Tierney et al., 2016a, Tierney et al., 2018a). Video verification of mouthguard-recorded impacts can improve the true positive rate of impact detection algorithms utilized by the devices but cannot assess false negatives (Wu et al., 2014). Only two camera views recording at 30 frames-per-second were available for each contact event meaning that player views were sometimes obstructed. It may be the case that helmet contact occurred as a secondary impact mechanism between video frames during certain inertial head loading events. Improved video quality and quantity would improve reliability in labelling events. Access to the camera systems utilised for broadcast video footage with higher frame rate video would be particularly useful for matches. Instrumented mouthguards can be susceptible to mandible interference, resulting in overestimation of head kinematics, particularly angular acceleration. However, mandible interference typically occurs at a particular frequency $(80-100 \mathrm{~Hz})$ that is faster than most American football impacts, and thus can be identified and removed from analysis and mitigated against with better mouthguard 
design (Kuo et al., 2016). Even though, custom-fit mouthguard were utilised, further work needs to be conducted on the influence of mouthguard fit on head kinematic measurement error. The sample size of seven players from a single college team during a subset of practices and matches is relatively small. Therefore, the purpose of this study was not to report head impact exposure. Despite the small sample size, kinematic magnitudes fall within the range of previously reported American football head kinematic measures (Beckwith et al., 2013). The detailed analysis and findings from this study can inform future larger-scale field study designs. For future work, equipping multiple teams for an entire season of matches and practices would be beneficial.

\section{Conclusion}

The study highlights the potential of combining qualitative video analysis with in-vivo head kinematics measurements. Head kinematics from inertial head loading events were of higher magnitude than direct helmet contacts events and occurred more frequently. This suggests that a number of direct helmet contact events sustained in American football are of similar magnitude to what is sustained during regular play (i.e. from inertial head loading). The study quantified the median head kinematics for blocking, blocked, tackling, tackled and ground contact events in American football, the magnitudes of which appear similar. The findings illustrate that it is important to include all contact events, including direct helmet contact and inertial head loading cases, when assessing head acceleration exposure and player load during a season of American football. Although it is important to coach contact technique for player performance, examining and monitoring the extent to which practices can be modified to reduce head acceleration exposure and severity is a necessary future step.

\section{Acknowledgements}

This research was funded by the Leeds Mobility Award

\section{Conflict of interest statement}

Some authors are developing the Stanford Mouthguard used in this study as a research device to study mild traumatic brain injury. Some of the authors are co-inventors on Stanford-owned patents related to head impact detection (patent 14/199,716: "Device for Detecting On-Body Impacts") and mechanical 
design (patent 15/373,454:"Oral Appliance for Measuring Head Motions by Isolating Sensors from Jaw Perturbance") of an instrumented mouthguard. This does not alter our adherence to the Journal of Biomechanics policies on sharing data and materials. 


\section{References}

ABRAHAMS, S., MC FIE, S., PATRICIOS, J., POSTHUMUS, M. \& SEPTEMBER, A. V. 2014. Risk factors for sports concussion: an evidence-based systematic review. British journal of sports medicine, 48, 91-97.

BARTSCH, A. J., HEDIN, D. S., GIBSON, P. L., MIELE, V. J., BENZEL, E. C., ALBERTS, J. L., SAMOREZOV, S., SHAH, A., STEMPER, B. S. \& MCCREA, M. M. 2019. Laboratory and On-field Data Collected by a Head Impact Monitoring Mouthguard. 41st Annual International Conference of the IEEE Engineering in Medicine and Biology Society. IEEE, 2068-2072.

BAUGH, C. M. \& KROSHUS, E. 2016. Concussion management in US college football: progress and pitfalls. Concussion, 1, CNC6.

BAUGH, C. M., STAMM, J. M., RILEY, D. O., GAVETT, B. E., SHENTON, M. E., LIN, A., NOWINSKI, C. J., CANTU, R. C., MCKEE, A. C. \& STERN, R. A. 2012. Chronic traumatic encephalopathy: neurodegeneration following repetitive concussive and subconcussive brain trauma. Brain imaging and behavior, 6, 244-254.

BECKWITH, J. G., GREENWALD, R. M., CHU, J. J., CRISCO, J. J., ROWSON, S., DUMA, S. M., BROGLIO, S. P., MCALlister, T. W., GUSKIEWICZ, K. M., MIHALIK, J. P., ANDERSON, S., SCHNEBEL, B., BROLINSON, P. G. \& COLLINS, M. W. 2013. Head impact exposure sustained by football players on days of diagnosed concussion. Medicine and Science in Sports and Exercise, 45, 737-46.

BROLINSON, P. G., MANOOGIAN, S., MCNEELY, D., GOFORTH, M., GREENWALD, R. \& DUMA, S. 2006. Analysis of linear head accelerations from collegiate football impacts. Current Sports Medicine Reports, 5, 23-8.

CROSS, M., KEMP, S., SMITH, A., TREWARTHA, G. \& STOKES, K. 2016. Professional Rugby Union players have a $60 \%$ greater risk of time loss injury after concussion: a 2-season prospective study of clinical outcomes. British journal of sports medicine, 50, 926-931. 
CUNNINGHAM, J., BROGLIO, S. \& WILSON, F. 2018. Influence of playing rugby on long-term brain health following retirement: a systematic review and narrative synthesis. BMJ open sport \& exercise medicine, 4, e000356.

DUMA, S. M., MANOOGIAN, S. J., BUSSONE, W. R., BROLINSON, P. G., GOFORTH, M. W., DONNENWERTH, J. J., GREENWALD, R. M., CHU, J. J. \& CRISCO, J. J. 2005. Analysis of real-time head accelerations in collegiate football players. Clinical Journal of Sport Medicine, 15, 3-8.

KAWATA, K., RUBIN, L. H., TAKAHAGI, M., LEE, J. H., SIM, T., SZWANKI, V., BELLAMY, A., TIERNEY, R. \& LANGFORD, D. J. J. O. N. 2017. Subconcussive impact-dependent increase in plasma S100 $\beta$ levels in collegiate football players. Journal of Neurotrauma, 34, 2254-2260.

KELLEY, M. E., ESPELAND, M. A., FLOOD, W. C., POWERS, A. K., WHITLOW, C. T., MALDJIAN, J. A., STITZEL, J. D. \& URBAN, J. E. 2018. Comparison of head impact exposure in practice drills among multiple youth football teams. Journal of Neurosurgery: Pediatrics, 23, 381-389.

KUO, C., WU, L., LOZA, J., SENIF, D., ANDERSON, S. C. \& CAMARILLO, D. B. 2018. Comparison of videobased and sensor-based head impact exposure. PLOS ONE, 13, e0199238.

KUO, C., WU, L. C., HAMMOOR, B. T., LUCK, J. F., CUTCLIFFE, H. C., LYNALL, R. C., KAIT, J. R., CAMPBELL, K. R., MIHALIK, J. P. \& BASS, C. R. 2016. Effect of the mandible on mouthguard measurements of head kinematics. Journal of biomechanics, 49, 1845-1853.

LESSLEY, D. J., KENT, R. W., FUNK, J. R., SHERWOOD, C. P., CORMIER, J. M., CRANDALL, J. R., ARBOGAST, K. B. \& MYERS, B. S. 2018. Video analysis of reported concussion events in the National Football League during the 2015-2016 and 2016-2017 seasons. The American journal of sports medicine, 46, 3502-3510.

MERCHANT-BORNA, K., ASSELIN, P., NARAYAN, D., ABAR, B., JONES, C. M. \& BAZARIAN, J. J. 2016. Novel method of weighting cumulative helmet impacts improves correlation with brain white matter changes after one football season of sub-concussive head blows. Annals of biomedical engineering, 44, 3679-3692. 
NATHANSON, J. T., CONNOLLY, J. G., YUK, F., GOMETZ, A., RASOULI, J., LOVELL, M. \& CHOUDHRI, T. 2016. Concussion incidence in professional football: position-specific analysis with use of a novel metric. Orthopaedic journal of sports medicine, 4, 2325967115622621.

NG, T. P., BUSSONE, W. R. \& DUMA, S. M. 2006. The effect of gender and body size on linear accelerations of the head observed during daily activities. Biomedical sciences instrumentation, 42, 25-30.

PELLMAN, E. J., VIANO, D. C., TUCKER, A. M., CASSON, I. R. \& WAECKERLE, J. F. 2003. Concussion in professional football: reconstruction of game impacts and injuries. Neurosurgery, 53, 799-812. ROWSON, S., DUMA, S. M., BECKWITH, J. G., CHU, J. J., GREENWALD, R. M., CRISCO, J. J., BROLINSON, P. G., DUhAIME, A. C., MCALlisteR, T. W. \& MAERLENDER, A. C. 2012. Rotational head kinematics in football impacts: an injury risk function for concussion. Annals of biomedical engineering, 40, 1-13.

STEMPER, B. D., SHAH, A. S., HAREZLAK, J., ROWSON, S., DUMA, S., MIHALIK, J. P., RIGGEN, L. D., BROOKS, A., CAMERON, K. L. \& GIZA, C. C. 2019. Repetitive head impact exposure in college football following an NCAA rule change to eliminate two-a-day preseason practices: a study from the NCAA-DoD CARE Consortium. Annals of biomedical engineering, 47, 2073-2085.

STEMPER, B. D., SHAH, A. S., HAREZLAK, J., ROWSON, S., MIHALIK, J. P., DUMA, S. M., RIGGEN, L. D., BROOKS, A., CAMERON, K. L. \& CAMPBELL, D. 2018. Comparison of head impact exposure between concussed football athletes and matched controls: evidence for a possible second mechanism of sport-related concussion. Annals of Biomedical Engineering, 47, 2057-2072.

STERN, R. A., RILEY, D. O., DANESHVAR, D. H., NOWINSKI, C. J., CANTU, R. C. \& MCKEE, A. C. 2011. Long-term consequences of repetitive brain trauma: chronic traumatic encephalopathy. $P M \& R, 3$, S460-7.

TALAVAGE, T. M., NAUMAN, E. A., BREEDLOVE, E. L., YORUK, U., DYE, A. E., MORIGAKI, K. E., FEUER, H. \& LEVERENZ, L. J. 2014. Functionally-detected cognitive impairment in high school football players without clinically-diagnosed concussion. Journal of neurotrauma, 31, 327-338. 
TIERNEY, G. J., JOODAKI, H., KROSSHAUG, T., FORMAN, J. L., CRANDALL, J. R. \& SIMMS, C. K. 2016 a. The kinematics of head impacts in contact sport: an initial assessment of the potential of model based image matching. ISBS-Conference Proceedings Archive. 108-111.

TIERNEY, G. J., JOODAKI, H., KROSSHAUG, T., FORMAN, J. L., CRANDALL, J. R. \& SIMMS, C. K. 2018a. Assessment of model-based image-matching for future reconstruction of unhelmeted sport head impact kinematics. Sports biomechanics, 17, 33-47.

TIERNEY, G. J., LAWLER, J., DENVIR, K., MCQUILKIN, K. \& SIMMS, C. 2016b. Risks associated with significant head impact events in elite rugby union. Brain Injury, 30, 1350-1361.

TIERNEY, G. J., RICHTER, C., DENVIR, K. \& SIMMS, C. K. 2018b. Could lowering the tackle height in rugby union reduce ball carrier inertial head kinematics? Journal of Biomechanics, 72, 29-36.

TIERNEY, G. J. \& SIMMS, C. K. 2017. The effects of tackle height on inertial loading of the head and neck in Rugby Union: A multibody model analysis. Brain Injury, 31, 1925-1931.

VIANO, D. C., CASSON, I. R. \& PELLMAN, E. J. 2007. Concussion in professional football: biomechanics of the struck player--part 14. Neurosurgery, 61, 313-27.

WU, L. C., LAKSARI, K., KUO, C., LUCK, J. F., KLEIVEN, S., CAMERON, R. \& CAMARILLO, D. B. 2016a. Bandwidth and sample rate requirements for wearable head impact sensors. Journal of biomechanics, 49, 2918-2924.

WU, L. C., NANGIA, V., BUI, K., HAMMOOR, B., KURT, M., HERNANDEZ, F., KUO, C. \& CAMARILLO, D. B. 2016b. In Vivo Evaluation of Wearable Head Impact Sensors. Annals of Biomedical Engineering, 44, 1234-45.

WU, L. C., ZARNESCU, L., NANGIA, V., CAM, B. \& CAMARILLO, D. B. 2014. A head impact detection system using SVM classification and proximity sensing in an instrumented mouthguard. IEEE Transactions on Biomedical Engineering, 61, 2659-2668.

XING, J., Al, H., LIU, L. \& LAO, S. 2010. Multiple player tracking in sports video: A dual-mode two-way bayesian inference approach with progressive observation modeling. IEEE Transactions on Image Processing, 20, 1652-1667. 

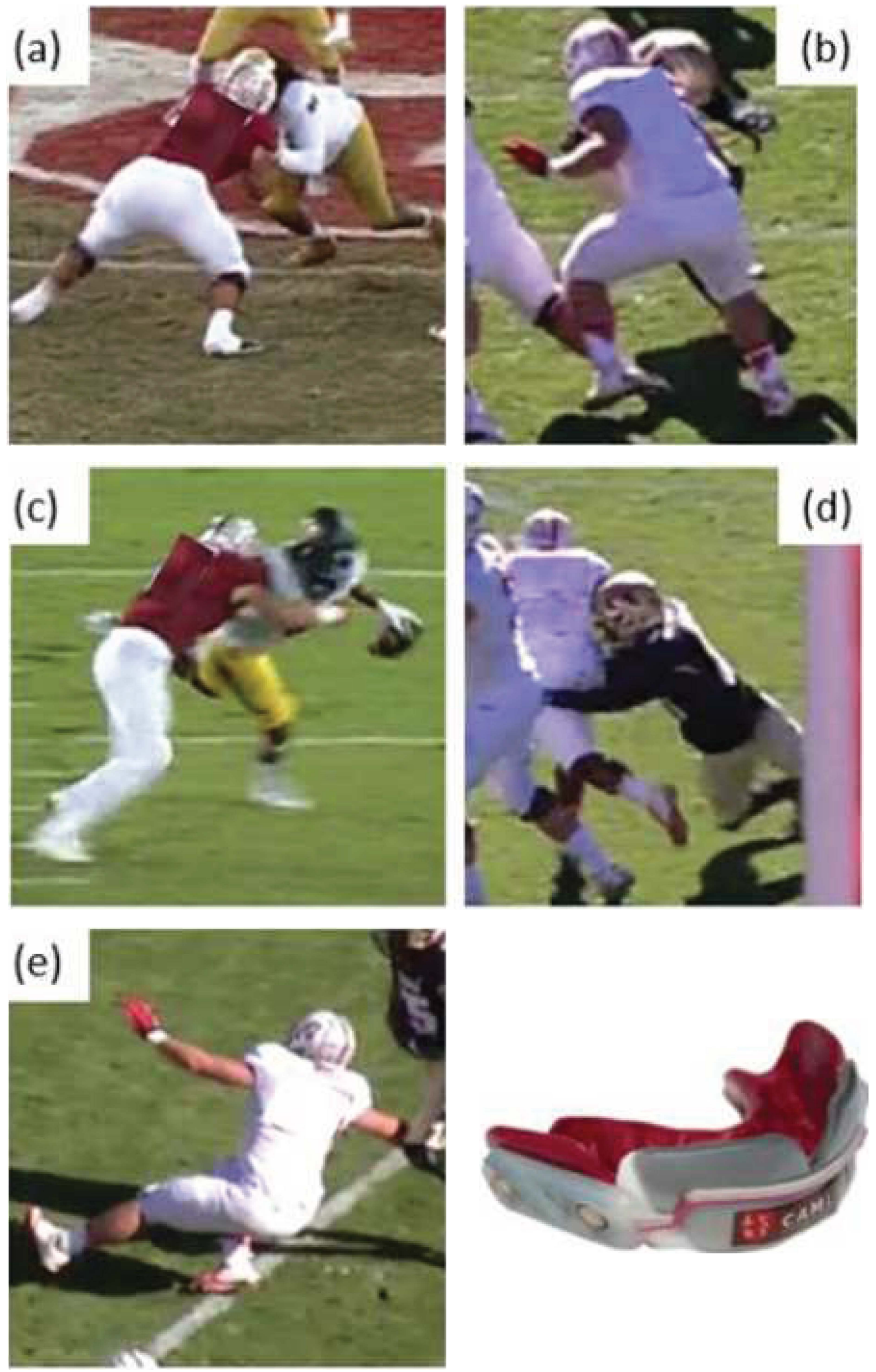

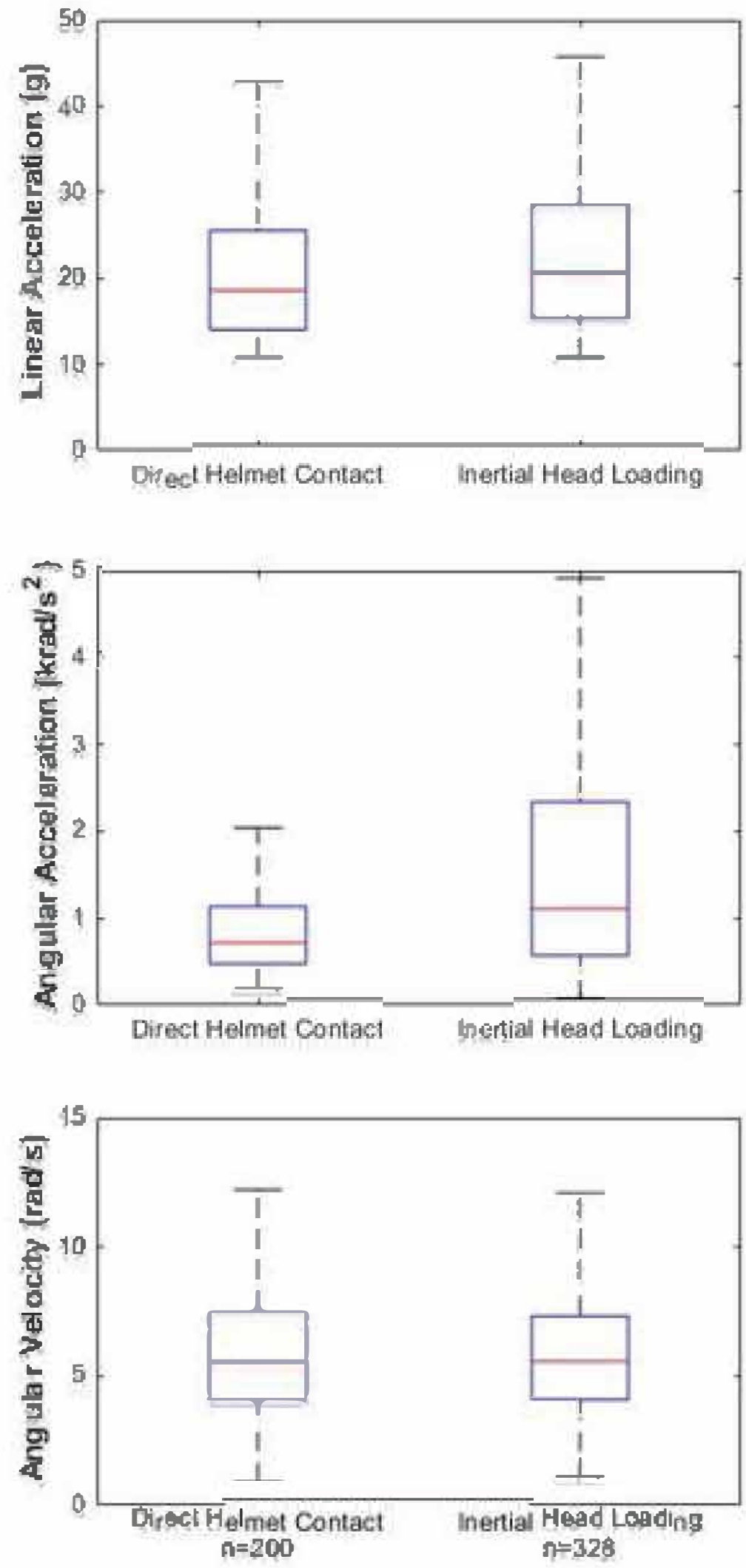

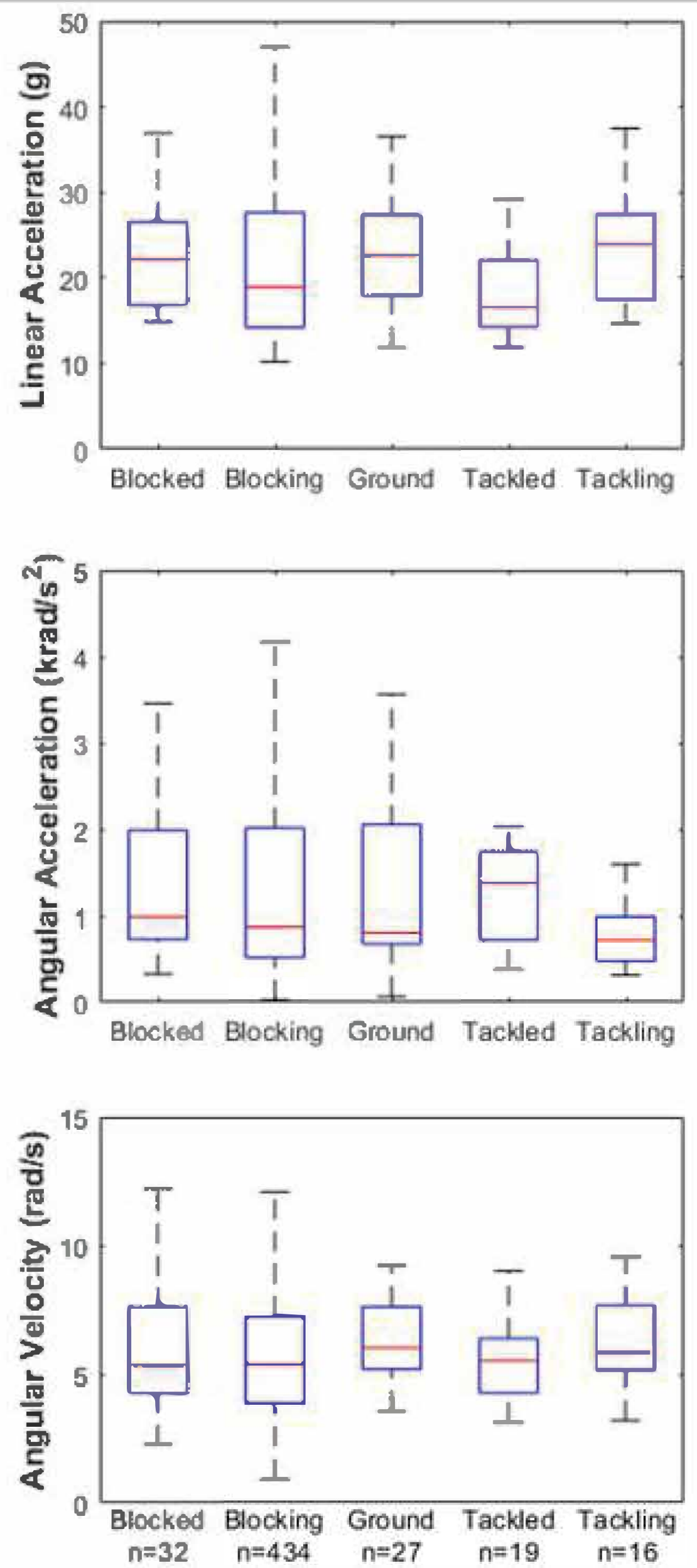
Table 1. The number of practices and matches the mouthguards were worn for each playing position.

\begin{tabular}{cccc}
\hline Position Category & Player Position & Matches & Practices \\
\hline \multirow{3}{*}{ Backs and Receivers } & Fullback & 1 & 4 \\
& Running Back & 2 & 5 \\
& Wide Receiver & 0 & 3 \\
\hline \multirow{3}{*}{ Offensive Linemen } & Tight End & 1 & 0 \\
& Guard & 1 & 4 \\
& Centre & 2 & 3 \\
\hline Linebackers & Inside Linebacker & 4 & 3 \\
\hline
\end{tabular}


Table 2. $\mathrm{p}$ values and effect size (with interpretation) from the linear mixed-effects model for contact event pairwise comparisons for linear acceleration, angular acceleration and angular velocity.

\begin{tabular}{|c|c|c|c|c|c|c|}
\hline & \multicolumn{2}{|c|}{$\underline{\text { Linear Acceleration }}$} & \multicolumn{2}{|c|}{$\underset{\text { Angular }}{\text { Acceleration }}$} & \multicolumn{2}{|c|}{$\underline{\text { Angular Velocity }}$} \\
\hline & $\begin{array}{c}\mathbf{p} \\
\text { value }\end{array}$ & $\begin{array}{l}\text { Effect } \\
\text { Size }\end{array}$ & $\begin{array}{c}\bar{p} \\
\text { value }\end{array}$ & $\begin{array}{c}\text { Effect } \\
\text { Size }\end{array}$ & $\underset{\text { value }}{\mathbf{p}}$ & $\begin{array}{l}\text { Effect } \\
\text { Size }\end{array}$ \\
\hline Blocked vs Blocking & 0.082 & $\begin{array}{c}0.330 \\
\text { (Small) }\end{array}$ & 0.105 & $\begin{array}{c}0.292 \\
\text { (Small) }\end{array}$ & 0.394 & $\begin{array}{c}0.149 \\
\text { (Trivial) }\end{array}$ \\
\hline Blocked vs Ground & 0.783 & $\begin{array}{c}0.068 \\
\text { (Trivial) }\end{array}$ & 0.385 & $\begin{array}{c}0.202 \\
\text { (Small) }\end{array}$ & 0.702 & $\begin{array}{c}0.089 \\
\text { (Trivial) }\end{array}$ \\
\hline Blocked vs Tackled & 0.305 & $\begin{array}{c}0.349 \\
\text { (Small) }\end{array}$ & 0.841 & $\begin{array}{c}-0.066 \\
\text { (Trivial) }\end{array}$ & 0.723 & $\begin{array}{c}-0.113 \\
\text { (Trivial) }\end{array}$ \\
\hline Blocked vs Tackling & 0.664 & $\begin{array}{c}0.133 \\
\text { (Trivial) }\end{array}$ & 0.436 & $\begin{array}{c}0.225 \\
\text { (Small) }\end{array}$ & 0.664 & $\begin{array}{c}0.124 \\
\text { (Trivial) }\end{array}$ \\
\hline Blocking vs Ground & 0.171 & $\begin{array}{c}-0.262 \\
\text { (Small) }\end{array}$ & 0.613 & $\begin{array}{c}-0.090 \\
\text { (Trivial) }\end{array}$ & 0.735 & $\begin{array}{c}-0.060 \\
\text { (Trivial) }\end{array}$ \\
\hline Blocking vs Tackled & 0.949 & $\begin{array}{c}0.019 \\
\text { (Trivial) }\end{array}$ & 0.209 & $\begin{array}{c}-0.358 \\
\text { (Small) }\end{array}$ & 0.336 & $\begin{array}{c}-0.262 \\
\text { (Small) }\end{array}$ \\
\hline Blocking vs Tackling & 0.509 & $\begin{array}{c}-0.198 \\
\text { (Trivial) }\end{array}$ & 0.814 & $\begin{array}{c}-0.067 \\
\text { (Trivial) }\end{array}$ & 0.928 & $\begin{array}{c}-0.025 \\
\text { (Trivial) }\end{array}$ \\
\hline Ground vs Tackled & 0.401 & $\begin{array}{c}0.281 \\
\text { (Small) }\end{array}$ & 0.404 & $\begin{array}{c}-0.268 \\
\text { (Small) }\end{array}$ & 0.518 & $\begin{array}{c}-0.201 \\
(\text { Small })\end{array}$ \\
\hline Ground vs Tackling & 0.843 & $\begin{array}{c}0.064 \\
\text { (Trivial) }\end{array}$ & 0.942 & $\begin{array}{c}0.023 \\
\text { (Trivial) }\end{array}$ & 0.908 & $\begin{array}{c}0.035 \\
\text { (Trivial) }\end{array}$ \\
\hline Tackled vs Tackling & 0.596 & $\begin{array}{l}-0.216 \\
\text { (Small) }\end{array}$ & 0.463 & $\begin{array}{c}0.290 \\
\text { (Small) }\end{array}$ & 0.535 & $\begin{array}{c}0.237 \\
\text { (Small) }\end{array}$ \\
\hline
\end{tabular}




\section{Figure Captions}

Figure 1. (a) Blocking (red jersey), (b) Blocked (white jersey), (c) Tackling (red jersey), (d) Tackled (white jersey), (e) ground contact event and (f) the instrumented mouthguard utilised for this study.

Figure 2. Median head kinematics (red line) with quartiles (box) and extremes (whiskers) based on direct helmet contact and inertial head loading events.

Figure 3. Median head kinematics (red line) with quartiles (box) and extremes (whiskers) based on contact event type. 